influence the internal stresses acting upon the dislocations forming the other boundaries of the, up to that moment, 'passive' lattice block and so induce its growth.

Laboratorium voor Physische Chemie der

Technische Hoogeschool, Delft.

Inderson, W. A., and Mehl, R. F., American Inst. Min. Met. Eng. Tech. Pub. No. 1805 (1945)

"Burgers, W. G., "Handb. d. Metallphysik", 3, 2 (1941) (Edwards Bros., Ann Ärbor, Mich., 1944)

Kornfeld, M., Phys. Z. Sovjet Union, 7, 432 (1935); see also ref. 2, $\S 100$.

- Sandee, J., Physica, 9, 741 (1942). Burgers, W. G., Physica, 9, 987 (1942)." Burgers, W. G., and May, W., Rec. Trav. Chim. Pays

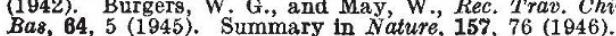

s Hull, F. C., Colton, R. A., and Mehl, R. F., Trans. A.I.M.E., 150, 185 (1942). Mehl, R. F., Sixteenth Campbell Memorial Lecture, Trans. A.S.M., 813 (184i).

- Burgers, W. G., Proc. Roy. Acad. Sci. Amsterdam, 50, 452 (1947).

${ }^{2}$ Cf. Bragg, W. L., Proc. Phys. Soc. London, 52, 54 (1940).

\section{Upper Yield Point: Occurrence in Bending Tests and Signification}

Mosi metals when stressed, after a certain elastic deformation, undergo a permanent elongation starting at the 'yield point'. In some materials, the stress then falls to a lower value; an 'upper yield point' occurs. Its existence has been doubted, but was recently well established for tensile stress ${ }^{1}$. Its physical significance has scarcely been explained. Further, its existence in bending tests has been denied.

We have carried out bending experiments in the Chevenard micromachine, in preference on $1.75 \mathrm{~mm}$. soft iron wire $(0.035$ per cent carbon) and on $2.00 \mathrm{~mm}$. carbon steel (1.2 per cent carbon).

In the soft iron, the upper yield point on bending was very plain. Fig. 1 shows two curves registered for single wires. $a$ is for annealed wire and shows a fairly plain upper yield point; $b$ is for the same wire, but slightly cold worked (by bending around a 2-cm. wooden rod, and then straightening); no upper yield point occurs.
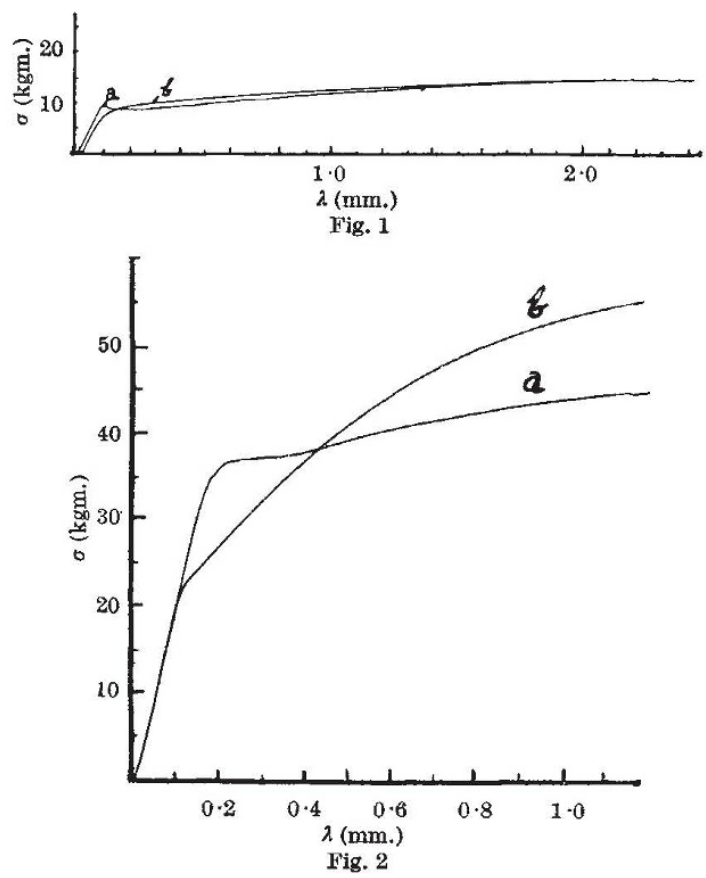

In Fig. 2, for 1.2 per cent carbon steel, curve $a$ is for the steel after a heat treatment which produced a precipitation of cementite $\left(\mathrm{Fe}_{\mathbf{3}} \mathrm{C}\right)$ along the grain boundaries; an upper yield point can be seen. Curve $b$ is for the same steel, heat-treated so as to contain merely spheroidized cementite; at the beginning it coincides with $a$, then deviating with no upper yield point.

This illustrates rather well the conclusion drawn from our experiments and micrographs; namely, an upper yield point is present when some hard precipitation occurs in the grain boundaries ${ }^{2}$. At high carbon content, this 'hard skeleton' is cementite, a fact already presumed by A. Pomp. At low carbon content, cementite may not be entirely excluded, but microscopical observations are in favour of an oxidic skeleton.

As soon as the hard skeleton--presenting an analogy with that of many organic tissues-is mechanically destroyed, the upper yield point disappears, as evidenced by Fig. 1, $b$.

From this point of view it is quite natural that the upper yield point occurs in bending tests, too.

It is an everyday experience that, on bending an annealed soft iron wire in one's fingers, the resulting bending is generally localized at one point, instead of forming an extended arch. This is due to the presence of an upper yield point in the wire. As soon as the reinforcing skeleton is broken at some place, the continued bending takes place preferentially there.

Laboratorium C. Benedicks,

Carl Benedicks ROMAN SKORSKI

Drottninggatan $95 \mathrm{~B}^{\mathrm{tI}}$, Stockholm Va.

1 Weibull, W., Jernkontorets Annaler, 126, 333 (1942).

${ }^{2}$ As expected by Benedicks, C., Jernkontorets Annaler, 129, 557 (1945).

\section{Large Strains and Displacements in Stress-Strain Problems}

I HAVE developed a theory that gives the relationship between the stresses and any finite values of displacement ${ }^{1}$ and strains ${ }^{2}$ in a loaded structure.

First consider a simple tensile test-bar under load. In this loaded bar deseribe an orthogonal element with edges $d R_{1}, d R_{2}, d R_{3}$ in the directions of the unit vectors $\mathbf{c}_{1}, \mathbf{c}_{2}, \mathbf{c}_{3}$ respectively, where $\mathbf{c}_{1}$ is in the direction of the load. Let the vector displacement $\mathbf{D}$ at any point have components $\mathbf{D}_{1}, \mathbf{D}_{2}, \mathbf{D}_{3}$. Then the relative displacement between the diagonally opposite corners of the element are,

$$
d \mathbf{D}=\sum_{i=1}^{3} \mathbf{c}_{i} \frac{\partial D_{i}}{\partial R_{i}} d R_{i}
$$

Now define the normal strains as,

$$
e_{i i}=\partial D_{i} / \partial R_{i} \text {. }
$$

Noting that the elemental length $d R_{i}$ is in the strained bar gives the definition of what I call a 'true' strain because it fits so naturally to the differential calculus analysis,

$$
e=\frac{\text { stretched length }- \text { initial length }}{\text { stretched length }} .
$$

On this definition strain never exceeds unity. This differs from the classical definition in which division is by the initial length.

If the load in the bar is divided by the actual cross-sectional area, this gives the 'true' stress $S_{11}$. 